\title{
RHOMBUS SHAPED RECONFIGURABLE MICROSTRIP ANTENNA FOR CDMA WIRELESS APPLICATIONS
}

\author{
K. Madhusudhana ${ }^{1}$ and S. Jagadeesha ${ }^{2}$ \\ Department of Electronics and Communication Engineering, SDM Institute of Technology, India \\ E-mail: ${ }^{1}$ madhusudhana.js@ @mail.com, ${ }^{2}$ jagadeesh.sd69@gmail.com
}

\begin{abstract}
Rhombus Shaped Reconfigurable microstrip antenna is designed to operate at $1.74 G \mathrm{~Hz}$. The proposed antenna is a Rhombus shaped microstrip antenna which gives a good size reduction with good impedance bandwidth in terms of with and without capacitor. The Designed antenna is expected to reduction in size and increase in Bandwidth. The Simulation is carried out by using IE3D software and practical results are measured by Vector Network analyzer. Comparative analysis has made between with and without capacitor as a lumped element. The size reduction of Rhombus shaped Reconfigurable microstrip antenna with capacitor gives best possible size reduction of $75.95 \%$ with overall bandwidth $86 \mathrm{MHz}$. Acceptable agreement is obtained between the simulated and measured antenna performance parameter.
\end{abstract}

Keywords:

Reconfigurable Microstrip Antenna, Wireless Application, Bandwidth, Reduced Size

\section{INTRODUCTION}

Microstrip antennas [1] are the most rapidly developing field in the last twenty years. Currently these antennas have a large application in mobile radio systems, integrated antennas, satellite navigation receivers, satellite communications, direct broadcast radio and television, etc. The considerable interest in microstrip antennas is due to their advantages compared to conventional microwave antennas as a lightweight, low volume, conformability, and ease of manufacture. One of the most serious disadvantages of microstrip antennas is their limited bandwidth.

Microstrip antenna (MSA) [2] has several advantages compared to the conventional microwave antennas. Some of advantages of microstrip antennas discussed by [3] are listed as follows:

- Light weight and low volume

- Low profile planar configuration which can be easily made conformal to host surface

- Low fabrication cost, hence can be manufactured in large quantities

- Supports both, linear as well as circular polarization

- Can be easily integrated with microwave integrated circuits (MICs)

- Capable of dual and triple frequency operations

- Mechanically robust when mounted on rigid surfaces

However microstrip antenna (MSA) suffers from many disadvantages compared to conventional antennas. Some of them are as follows:

- Narrow bandwidth

- Quite large size for lower microwave frequencies
- Low efficiency

- Low Gain

- Extraneous radiation from feeds and junctions

- Poor end fire radiator except tapered slot antennas

- Low power handling capacity

However, there are ways of substantially diminishing the effects of these disadvantages. The techniques to overcome the first two limitations are discussed extensively in this paper. The limitation of MSA can overcome by using a Reconfigurable concept with microstrip antenna.

Reconfigurable antenna has a significant Potential in the modern wireless communication. This is as a result of the reduction in antenna size and cost, and convenience for certain applications to operate with a single antenna than multiple Antennas [4]-[5]. Moreover, these reconfigurable antennas have interesting characteristics as they can provide various features in different operating frequencies [6]-[7], polarizations [8], [9], and radiation patterns [10], [11] by changing the current distribution over the volume of the antennas.

\section{LITERATURE REVIEW}

T.A. Denidni and N. Hassaine [12] reported that antenna operates at the frequency band from $4.8 \mathrm{GHz}$ to $6.0 \mathrm{GHz}$. M.R. Tayfeh Aligodaz and K. Forooraghi [13] reported that antenna can attain $72 \%$ size reduction as well as $17 \%$ impedance bandwidth. M. Ali and R. Dougal [14] reported that the antenna is designed to function in the $5 \mathrm{GHz}$ to $6 \mathrm{GHz}$ wireless band. N. Ramali and M.T. Ali [5] reported that antenna operates at the frequency band from $2.6 \mathrm{GHz}$ to $3.5 \mathrm{GHz}$.

From the above literature review it found that most of work is carried on higher frequency band, so our designed antenna is to operate at lower frequency band and reduces its size by introducing a lumped element as capacitor.

\section{ANTENNA DESIGN}

Rhombus shaped microstrip patch antenna are designed with three essential parameters are:

i. Frequency of operation $\left(f_{0}\right)$ : The resonant frequency of the antenna must be selected appropriately which is able to operate under desired frequency range. The frequency of operation in this design is $1.8 \mathrm{GHz}$.

ii. Dielectric constant of the substrate $\left(\varepsilon_{r}\right)$ : The dielectric material selected for design is glass epoxy which has a dielectric constant 4.4 .

iii. Height of dielectric substrate $(h)$ : For the microstrip patch antenna to be used in cellular phones, it is connected that 
the antenna should not be bulky. Hence, the height of the dielectric substrate is selected as $1.6 \mathrm{~mm}$.

\subsection{DESIGN OF MICROSTRIP LINE FEEDING}

The microstrip antenna is designed by using the following formula,

$$
\lambda_{0}=\frac{c}{f}
$$

where, $f$ is the resonating frequency.

Width of patch,

$$
W=\frac{c}{2 f_{r}}\left(\frac{\varepsilon_{r}+1}{2}\right)^{-\frac{1}{2}}
$$

Effective length,

$$
\Delta L=0.412 h * \frac{\left(\varepsilon_{e}+0.3\right)\left(\frac{w}{h}+0.264\right)}{\left(\varepsilon_{e}-0.258\right)\left(\frac{w}{h}+0.8\right)}
$$

where, $\varepsilon_{e}=\frac{\varepsilon_{r}+1}{2}+\frac{\varepsilon_{r}-1}{2}\left[1+12 \frac{h}{w}\right]^{-\frac{1}{2}}$

Length of Patch,

$$
L=\frac{c}{2 f_{r} \sqrt{\varepsilon_{e}}}-2 \Delta L
$$

Let, $Z_{o}=50 \Omega, \varepsilon_{r}=4.4 ; \quad \varepsilon_{r}=4.4$;

$$
\frac{W}{d}=\frac{8 e^{A}}{e^{A}-2} \text { for } \frac{W}{d}<2
$$

where, $A=\frac{Z}{60} \sqrt{\left(\varepsilon_{r}+1\right) / 2}+\frac{\varepsilon_{r}-1}{\varepsilon_{r}+1}\left(0.23+\frac{0.11}{\varepsilon_{r}}\right)$;

$$
\frac{W}{d}=\frac{2}{n}\left[B-1-\ln (2 B-1)+\frac{\varepsilon_{r}-1}{2 \varepsilon_{r}}\left\{\ln (B-1)+0.39-\frac{0.6}{\varepsilon_{r}}\right\}\right]
$$

for $\frac{W}{d}>2$, where $B=\frac{377 \pi}{2 Z_{o} \sqrt{\varepsilon_{r}}}$;

Let us assume $\frac{W}{d}>2$,

$$
R_{\text {in }}=\frac{\left(120 \lambda_{o}\right)^{2}+\left(\frac{377 h}{L \sqrt{\varepsilon_{r}}}\right)^{2} \tan ^{2} \beta l}{240 * l * \lambda_{o}\left(1+\tan ^{2} \beta l\right)}
$$

where, $l=\left(\frac{\theta}{\beta}\right)\left(\frac{\pi}{180}\right) \beta=\frac{2 \pi \sqrt{\varepsilon_{r}}}{\lambda_{o}} ; \lambda_{g}=\frac{\lambda_{o}}{\sqrt{\varepsilon_{e}}} ; L_{f}=\frac{\lambda_{g}}{4}$

The optimized geometry of proposed rhombic microstrip antenna is as shown in Fig.1. The Rhombus shaped microstrip antenna whose size is of $41 \mathrm{~mm} \times 41 \mathrm{~mm}$ is printed on a dielectric substrate of thickness $1.6 \mathrm{~mm}$. The material used in glass epoxy with dielectric permittivity of $\varepsilon_{r}=4.4$ which is designed to operate at $1.8 \mathrm{GHz}$. This antenna is fed by microstrip line of dimension $\left(L_{f} 50, W_{f} 50\right)=15 \mathrm{~mm}, 4.84 \mathrm{~mm}$ through quarter wave transformer having $\left(L_{t} 50, W_{t} 50\right)=24.05 \mathrm{~mm}, 0.72 \mathrm{~mm}$. They are mounted on ground plane of dimension $(106.225 \times 77.182756) \mathrm{mm}^{2}$ through $50 \Omega$ SMA connector. The rhombic shape of zeroth iteration is a conventional square. In zeroth iteration, this curve begins as a straight line imposed upon the sides of the square. Next, another square of side length each side of the square is removed. The antennas are initially simulated using IE3D software and all the parameters are optimized and they are as follows:

$h=1.6 \mathrm{~mm} ; L=41.08 \mathrm{~mm} ; W=41.08 \mathrm{~mm}$;

$L_{s}=10.27 \mathrm{~mm} ; W_{s}=10.27 \mathrm{~mm} ; L_{t}=24.05 \mathrm{~mm} ;$

$W_{t}=0.72 \mathrm{~mm} ; L_{f}=15 \mathrm{~mm} ; W_{f}=4.84 \mathrm{~mm}$

Capacitor used is $0.1 \mu \mathrm{F}$.

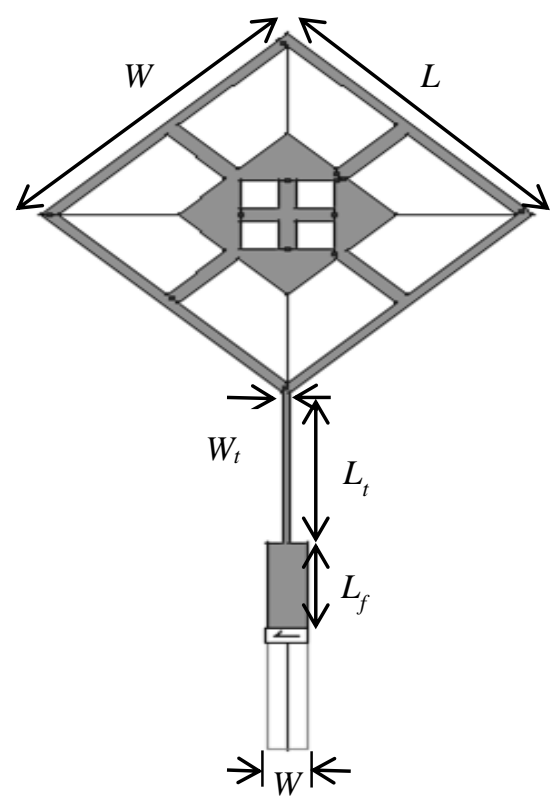

Fig.1. Rhombus shaped microstrip antenna

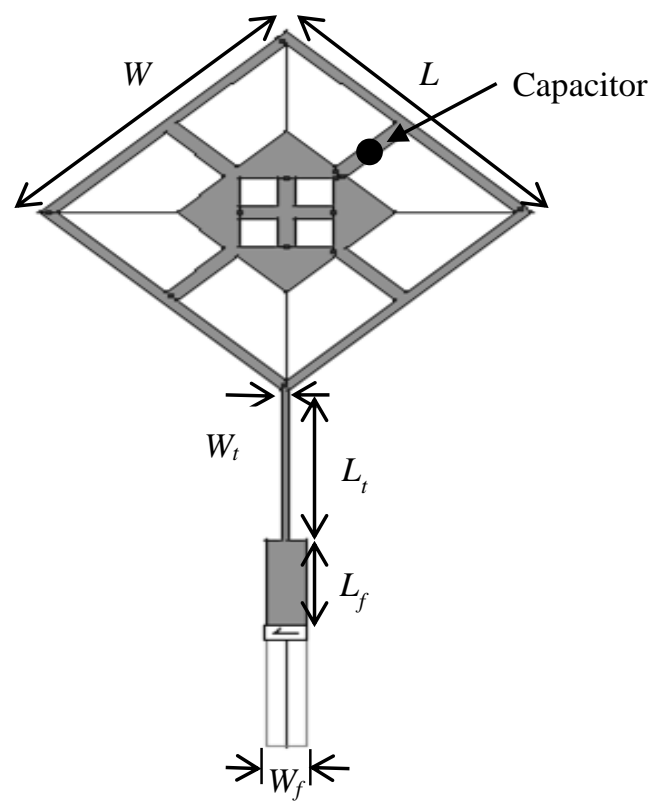

Fig.2. Rhombus shaped Reconfigurable microstrip antenna 
Photograph of antenna with top and bottom view is as shown in Fig.3 and Fig.4.

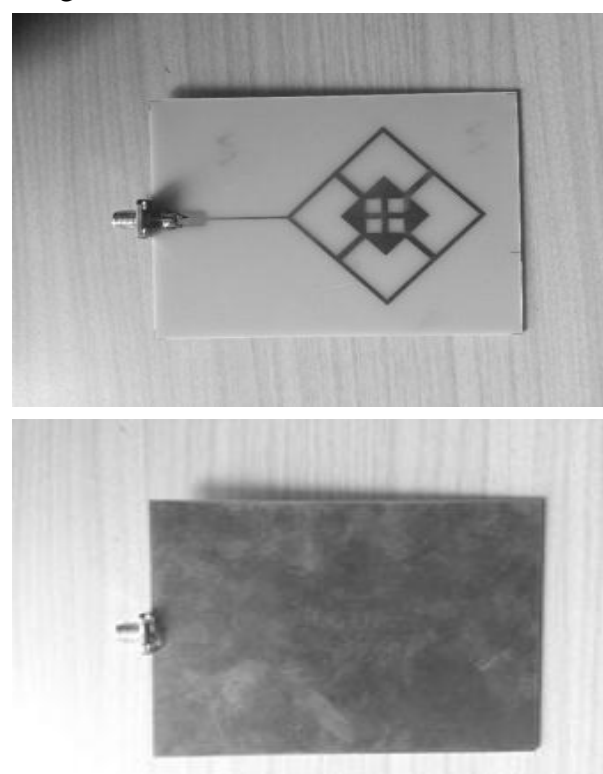

Fig.3. Front and back view of Rhombus shaped microstrip antenna without capacitor
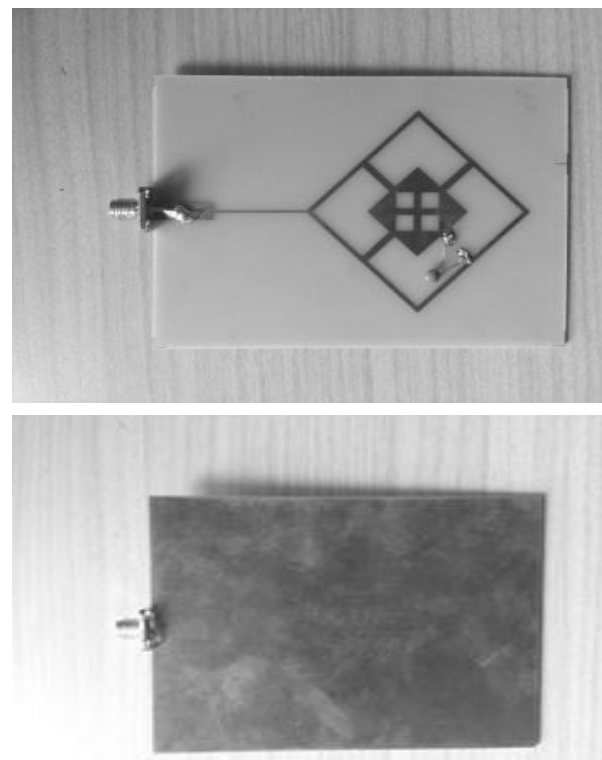

Fig.4. Front and back view of Rhombus shaped microstrip antenna with capacitor

\section{RESULTS}

The Fig.5 and Fig.7 show the simulated Return loss of Rhombus shaped microstrip antenna without and with capacitor. The Fig.6 and Fig. 8 show the practical Return loss of Rhombus shaped microstrip antenna without and with capacitor.

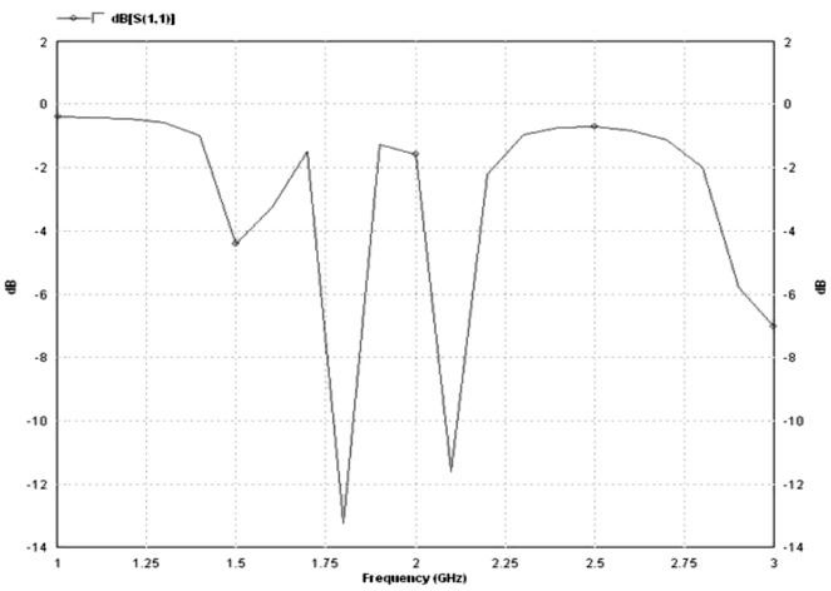

Fig.5. Return loss of Rhombus shaped microstrip antenna without capacitor

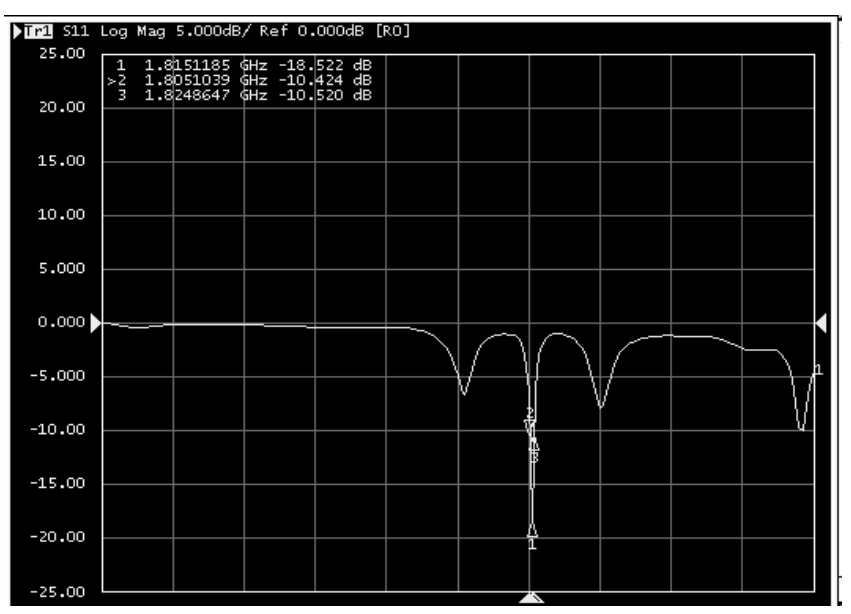

Fig.6. Practical Return loss of Rhombus shaped microstrip antenna

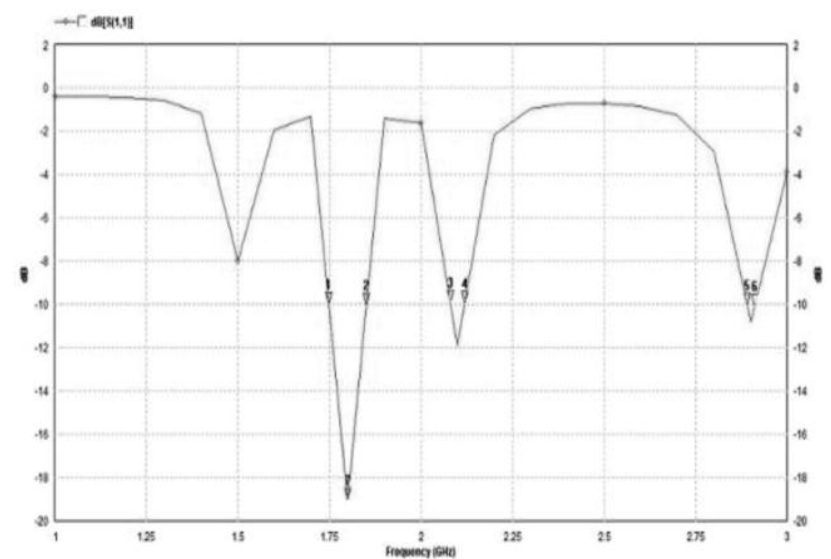

Fig.7. Return Loss of Reconfigurable shaped microstrip antenna with capacitor 


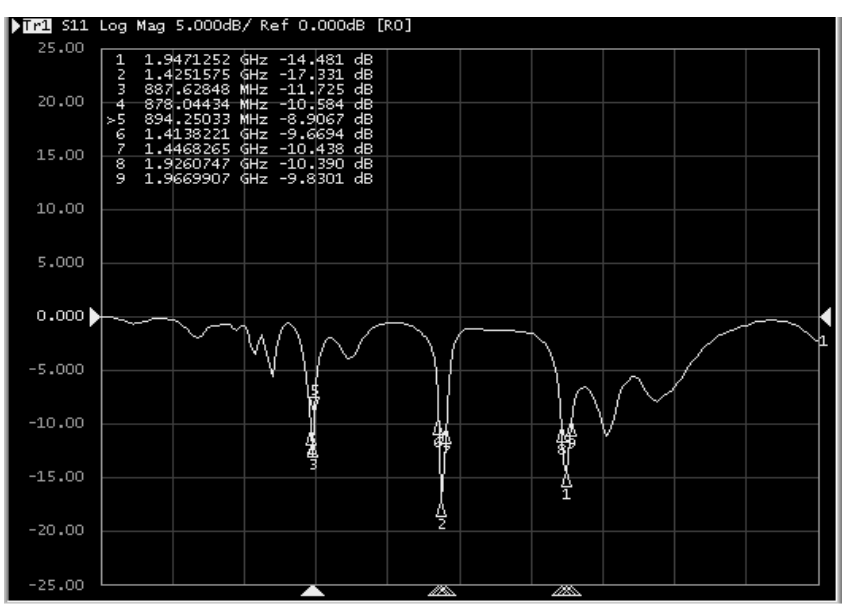

Fig.8. Practical Return Loss of Reconfigurable shaped microstrip antenna with capacitor

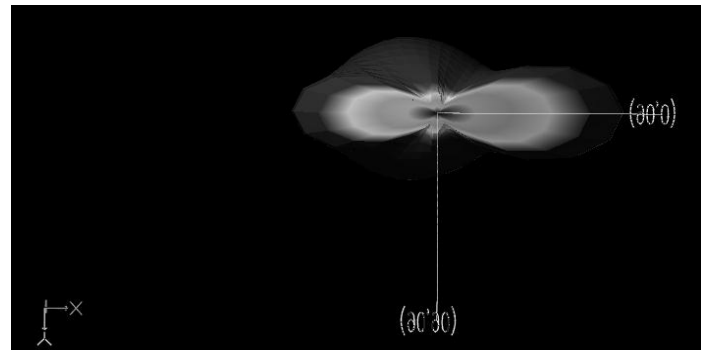

Fig.9. Radiation characterization

Table.1. Results of the proposed antenna

\begin{tabular}{|c|c|c|c|c|c|c|c|c|c|}
\hline \multirow[t]{2}{*}{$\begin{array}{l}\text { Sl. } \\
\text { No. }\end{array}$} & \multirow[t]{2}{*}{$\begin{array}{c}\text { Prototype } \\
\text { Antenna }\end{array}$} & \multicolumn{2}{|c|}{$\begin{array}{c}\text { Resonant } \\
\text { Frequency } \\
f_{r}(\mathbf{G H z})\end{array}$} & \multicolumn{2}{|c|}{$\begin{array}{l}\text { Return Loss } \\
\quad \text { (dB) }\end{array}$} & \multicolumn{2}{|c|}{$\begin{array}{c}\text { Bandwidth } \\
\text { (MHz) }\end{array}$} & \multicolumn{2}{|c|}{$\begin{array}{c}\text { Overall } \\
\text { Bandwidth } \\
\text { (MHz) }\end{array}$} \\
\hline & & Sim. & Pract. & Sim. & Pract. & Sim. & Pract. & Sim. & Pract. \\
\hline \multirow[b]{2}{*}{1} & \multirow{2}{*}{$\begin{array}{l}\text { Structured } \\
\text { Antenna } \\
\text { without } \\
\text { capacitor }\end{array}$} & 1.8 & 1.8 & -13.1 & -18 & 60 & 20 & \multirow[b]{2}{*}{66} & \multirow[b]{2}{*}{20} \\
\hline & & 2.1 & 2.8 & -11.8 & -10 & 6 & 0 & & \\
\hline \multirow{3}{*}{2} & \multirow{3}{*}{$\begin{array}{l}\text { Structured } \\
\text { Antenna } \\
\text { with } \\
\text { capacitor }\end{array}$} & 1.8 & 0.89 & -11 & -11 & 30 & 16 & \multirow{3}{*}{160} & \multirow{3}{*}{86} \\
\hline & & 2.09 & 1.4 & -12 & -17.3 & 40 & 30 & & \\
\hline & & 2.89 & 1.9 & -19 & -14.4 & 90 & 40 & & \\
\hline
\end{tabular}

Instrument used to measure the practical return loss using vector network analyzer as shown in Fig.10.

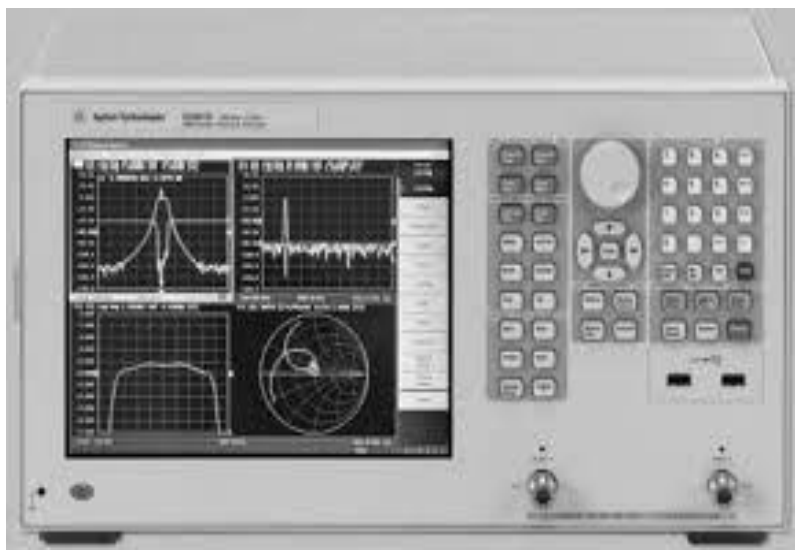

Fig.10. Vector Network Analyzer

\section{CONCLUSION}

Rhombus Shaped Reconfigurable microstrip antenna is designed by using a lumped element as capacitor it gives a best size reduction of $75.95 \%$ with reference to without capacitor. Overall bandwidth of $20 \mathrm{MHz}$ for rhombus shaped antenna without capacitor and overall bandwidth of $86 \mathrm{MHz}$ for rhombus shaped antenna with capacitor respectively. The overall bandwidth of rhombus shaped antenna with capacitor is 4.3 times more than the overall bandwidth of rhombus shaped antenna without capacitor. The antenna performance is suitable for handheld devices which covering the wireless communication band i.e. full coverage of CDMA application and partial coverage of DCS application.

\section{REFERENCES}

[1] H. Wang, X.B. Huang, D.G. Fang and G.B. Han, "A Microstrip Antenna Array Formed by Microstrip Line Fed Tooth-Like-Slot Patches", IEEE Transactions on Antennas and Propagation, Vol. 55, No. 4, pp. 1210-1214, 2007.

[2] Kai Fong Lee and Wei Chen, "Advances in Microstrip and Printed Antennas", John Wiley, 1997.

[3] Jean-Francois Zurcher and Fred E. Gardiol, "Broadband Patch Antennas", First Edition, Artech House, 1995.

[4] Preet Kaur, Asok De and S.K. Aggarwal, "Design of a Novel Reconfigurable Fractal Antenna for Multiband Application", International Journal of Advanced Science and Technology, Vol. 62, pp. 103-112, 2014.

[5] N. Ramli, M.T. Ali, M.T. Islam, A.L. Yusof, S. MuhamudKayat and A.A. Azlan, "Design of an Aperture-Coupled Frequency-Reconfigurable Microstrip Stacked Array Antenna for LTE and WiMAX Applications", ISRN Communications and Networking, Vol. 2014, pp. 1-11, 2014.

[6] B.A. Cetiner, G.R. Crusats, L. Jofre and Necmi Biyikli, "RF MEMS Integrated Frequency Reconfigurable Annular Slot Antenna", IEEE Transactions on Antennas and Propagation, Vol. 58, No. 3, pp. 626-632, 2010.

[7] S. Muhamud-Kayat, M.T. Ali, M.K. Mohd Salleh, M.H. Mohd Rusli, N. Ramli and H. Alias, "Truncated RhombusLike Slotted Antennas with Aperture Coupling Technique", Progress in Electromagnetics Research Letters, Vol. 39, pp. 181-198, 2013.

[8] J. Perruisseau-Carrier, "Dual-Polarized and PolarizationFlexible Reflective Cells with Dynamic Phase Control", IEEE Transactions on Antennas and Propagation, Vol. 58, No. 5, pp. 1494-1502, 2010.

[9] F. Ferrero, C. Luxey, R. Staraj and G. Jacquemod, "A Novel Quad-Polarization Agile Patch Antenna", IEEE Transactions on Antennas and Propagation, Vol. 57, No. 5, pp. 1563-1567, 2009.

[10] D. Rodrigo, J. Romeu, S. Capdevila and L. Jofre, "A Figureof-Merit for Pattern Reconfigurable Antennas", IEEE Transactions on Antennas and Propagation, Vol. 61, No. 3, pp. 1448-1453, 2013.

[11] Yan-Ying Bai, Shaoqiu Xiao, Ming-Chun Tang, Zhuo-Fu Ding and Bing-Zhong Wang, "Wide-Angle Scanning Phased Array With Pattern Reconfigurable Elements", IEEE 
Transactions on Antennas and Propagation, Vol. 59, No. 11, pp. 4071-4076, 2011.

[12] T.A. Denidni and N. Hassaine, "Broadband and High Gain E-Shaped Microstrip Antenna for High-Speed Wireless Networks", Progress in Electromagnetic Research C, Vol. 1, pp. 105-111, 2008.

[13] M.R. Tayfeh Aligodaz, K. Forooraghi and A. Rashidian, "Wideband Miniaturized L-Probe Fed Fractal Clover Leaf
Microstrip Patch Antenna", Proceedings of $13^{\text {th }}$ International Symposium on Antennas, 2004.

[14] M. Ali, R. Dougal, G. Yang and H.S. Hwang, "Wideband Circularly Polarized Microstrip Patch Antenna for Wireless LAN Applications", Proceedings of IEEE Antennas and Propagation Society International Symposium, Vol. 2, pp. 34-37, 2003. 